\title{
Low-cost and Multiplexable Whole mRNA-Seq Library Preparation Method with Oligo-dT Magnetic Beads for Illumina Sequencing Platforms \\ Makoto Kashima ${ }^{1} \$$, Ayumi Deguchi ${ }^{1}$, Ayumi Tezuka ${ }^{1}$ and Atsushi J. Nagano ${ }^{2, *}$
}

\begin{abstract}
${ }^{1}$ Research Institute for Food and Agriculture, Ryukoku University, Shiga, Japan; ${ }^{2}$ Faculty of Agriculture, Ryukoku University, Shiga, Japan; ${ }^{\$}$ Current address: Department of Chemistry and Biological Science, College of Science and Engineering, Aoyama Gakuin University, Sagamihara, Japan

*For correspondence: anagano@agr.ryukoki.ac.jp
\end{abstract}

\begin{abstract}
[Abstract] RNA-Seq is a powerful method for transcriptome analysis used in varied field of biology. Although several commercial products and hand-made protocols enable us to prepare RNA-Seq library from total RNA, their cost are still expensive. Here, we established a low-cost and multiplexable whole mRNA-Seq library preparation method for illumine sequencers. In order to reduce cost, we used costeffective and robust commercial regents with small reaction volumes. This method is a whole mRNASeq, which can be applied even to non-model organisms lacking the transcriptome references. In addition, we designed large number of 3' PCR primer including 8 nucleotides barcode sequences for multiplexing up to three hundreds samples. To summarize, it is possible with this protocol to prepare 96 directional RNA-Seq libraries from purified total RNA in three days and can be pooled for up to three hundred libraries. This is beneficial for large scale transcriptome analysis in many fields of animals and plant biology.
\end{abstract}

Keywords: RNA-Seq, mRNA, Multiplexing, Transcriptome, Illumina

[Background] In the last decade, sequencing cost has been reduced drastically thanks to the advance in massive parallel sequencing technologies (Muir et al., 2016). On the other hand, the cost at library preparation step stands out. For example, commercial kits for RNA-Seq library preparation such as TruSeq RNA Library Prep Kit (illumine, USA) and NEBNext Ultra RNA Library Prep Kit (NEB, USA) cost around 40-60 dollars per sample. Recently, several studies have developed cost-effective RNA-Seq library preparation methods (Kumar et al., 2012; Nagano et al., 2015; Townsley et al., 2015; Alpern et al., 2019; Kamitani et al., 2019). Particularly, 3' RNA-Seq protocols (Lasy-Seq and BRB-Seq), enable early-pooling of samples resulting in reducing the cost into about two dollar per sample (Alpern et al., 2019; Kamitani et al., 2019). While 3' RNA-Seq is economically superior to whole mRNA-Seq method, whole mRNA-Seq can sequence full-length of RNA. Thus, whole mRNA-Seq is good for detection of splicing variants and novel transcripts. Although our previously-developed protocol of whole mRNA-Seq using rRNA depletion is cheap (Nagano et al., 2015), it requires many kinds of antisense oligo against rRNA and enzymes for reverse transcription, $2^{\text {nd }}$ strand synthesis, end-repair, A-tailing, adapter ligation and library amplification. In this protocol, (1) we replaced rRNA depletion against mRNA-purification using oligo-dT beads in order to reduce initial cost. (2) Enzymes required for end-repair to library amplification were replaced with KAPA Hyper Prep Kit (Roche, Switzerland); this simplification increases 
reaction efficiency as well as reduce labor. (3) We saved reaction volumes throughout all steps $(\leq 20 \mu \mathrm{l})$, which saves cost and enables handling even with 384-well plates. The required cost is approximately one-third of the golden standard kits. (4) We designed 300 kinds of $3^{\prime}$ PCR primers with barcode sequences for multiplexing, which enabled us to sequence 300 samples at a time with a cost-effective and ultra-high-throughput sequencer such as NovaSeq.

\section{Materials and Reagents}

1. $0.2 \mathrm{ml} \mathrm{PCR}$ tubes

2. Pipette tips

3. $5 \times$ Super Script IV buffer (Invitrogen)

4. DTT (Invitrogen)

5. Dynabeads ${ }^{\circledR}$ Oligo (dT)25 (Thermo Fisher scientific)

6. Total RNA

7. Random primer $(\mathrm{N})_{6}(\mathrm{TaKaRa})$

8. dNTP (25 mM each) (Promega)

9. SuperScript IV (Invitrogen)

10. Actinomycin $D(1,000 \mathrm{ng} / \mathrm{\mu l})$ (Nacalai Tesque)

11. AMPure XP (Beckman Coulter)

12. $\mathrm{EtOH}$

13. Nuclease-free water

14. 10× Blue Buffer (Enzymatics)

15. RNase $H$ (Enzymatics)

16. DNA polymerase I (Enzymatics)

17. KAPA Hyper prep kit (KAPA Biosystems)

18. Tris- $\mathrm{HCl}$

19. $\mathrm{LiCl}$

20. EDTA

21. DNA glycosylase (UDG) (Enzymatics)

22. KAPA HiFi HotStart ReadyMix (2x) (KAPA Biosystems)

23. KAPA Library Quantification Kit Illumina (KAPA Biosystems)

24. Agilent High Sensitivity DNA kit (Agilent Technologies)

25. $2 \times$ binding buffer (see Recipes)

26. Washing buffer (see Recipes)

\section{Equipment}

1. MagnaStand YS-model (FastGene)

2. Agilent 2100 Bioanalyzer (Agilent Technologies) 
3. Quantitative PCR instrument

4. Pipette

5. Thermal cycler

\section{Procedure}

In this protocol, we used MagnaStand YS-model (FastGene) in nucleotide acid purification with magnetic beads. All experiments were conducted in $0.2 \mathrm{ml} \mathrm{PCR}$ tubes. Reaction solutions should be mixed by tapping or inversion. All operations should be conducted under a DNA/RNA-free environment. The overview of this protocol is shown in Figure 1.

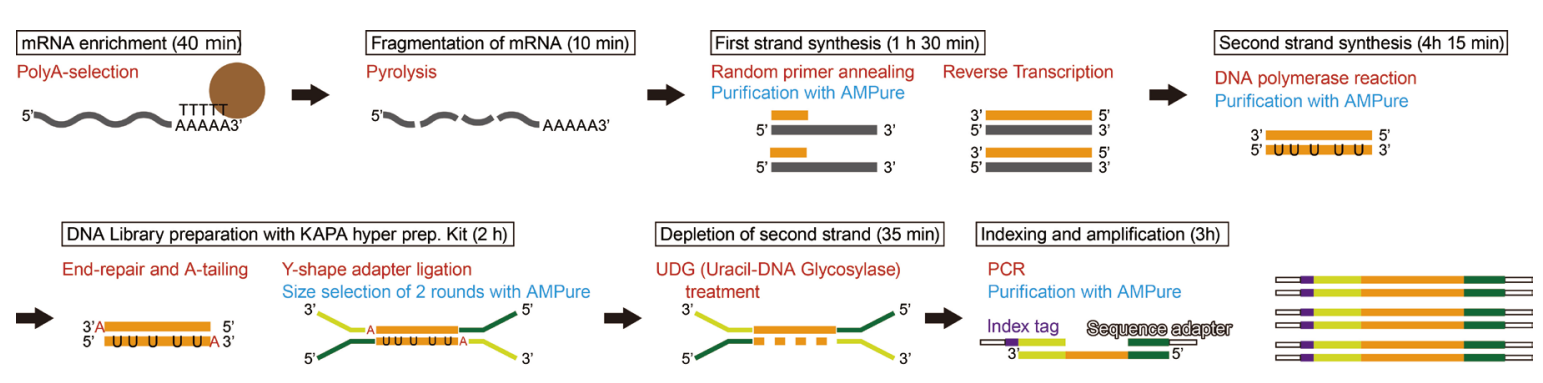

Figure 1. The protocol flow chart of this protocol. The approximate time required is shown for each step.

A. mRNA purification

1. Wash $15 \mu \mathrm{l}$ of Dynabeads ${ }^{\circledR}$ Oligo (dT)25 (Thermo Fisher Scientific) twice each with $50 \mu \mathrm{l}$ of $2 \times$ binding buffer (Recipe 1) using Magna Stand for $0.2 \mathrm{ml} \mathrm{PCR} \mathrm{Tube} \mathrm{(FastGene)} \mathrm{and} \mathrm{then}$ resuspend the beads in $30 \mu \mathrm{l}$ of $2 \times$ binding buffer for the later use.

'Wash' indicates:
a. Put on a magnet, $5 \mathrm{~min}$, remove supernatant.
b. Add $2 \times$ binding buffer and mix by pipetting.
c. Repeat.

2. Denature total RNA (more than $1 \mu \mathrm{g}$ and RIN $>7.0$ is recommended) in $30 \mu \mathrm{l}$ of distilled water or $10 \mathrm{mM}$ Tris $\cdot \mathrm{HCl}(\mathrm{pH} 8.5)$ at $65^{\circ} \mathrm{C}$ for $2 \mathrm{~min}$ and then immediately transfer onto ice. All thermal control procedures in this protocol can be processed in a thermal cycler. Then add $30 \mu \mathrm{l}$ of the washed Dynabeads ${ }^{\circledR}$ Oligo (dT)25. Mix the mixture well by pipetting and incubate at room temperature for $10 \mathrm{~min}$. And next wash the mixture with $70 \mu \mathrm{l}$ of washing buffer (Recipe 2 ) twice using the Magna Stand.

'Wash' indicates:
a. Put on a magnet, 5 min, remove supernatant.
b. Add washing buffer and mix by pipetting.
c. Repeat. 
3. Elute the RNA in $30 \mu \mathrm{l}$ of pre-warmed distilled water at $80^{\circ} \mathrm{C}$ for 5 min and then immediately chill on ice. For a second round of polyA-selection, add $30 \mu \mathrm{l}$ of $2 \times$ binding buffer to the solution, and incubate at room temperature for $10 \mathrm{~min}$. Again, wash the mixture with $70 \mu \mathrm{l}$ of washing buffer twice using the Magna Stand. Elute the RNA in $14 \mu \mathrm{l}$ of pre-warmed distilled water at $80{ }^{\circ} \mathrm{C}$ for $2 \mathrm{~min}$, then immediately place on the magnet and collect into a new tube. The expected volume of the product is $13 \mu \mathrm{l}$, with which the following experiments may only be performed twice at most.

\section{B. RNA-seq library preparation and sequencing}

1. Mix $5 \mu$ l of purified mRNA obtained in the above section with $4 \mu \mathrm{l}$ of $5 \times$ Super Script IV buffer (Invitrogen) and $1 \mu \mathrm{l}$ of frozen stock of $100 \mathrm{mM}$ DTT (Invitrogen).

2. mRNA is fragmented by incubating at $94^{\circ} \mathrm{C}$ for $4.5 \mathrm{~min}$ and then immediately cooled down on ice.

3. Then add $0.6 \mu \mathrm{l}$ of $100 \mu \mathrm{M}$ random primer $(\mathrm{N})_{6}($ TaKaRa) and $0.9 \mu \mathrm{l}$ of distilled water to the fragmented mRNA. The volume of the mix is $12 \mu \mathrm{l}$.

4. Incubate the mixture at $50{ }^{\circ} \mathrm{C}$ for $5 \mathrm{~min}$ and immediately chill on ice to relax the secondary structures of the mRNA.

5. Add the reverse transcription master mix ( $1 \mu \mathrm{l}$ of frozen stock of $100 \mathrm{mM} \mathrm{DTT}, 0.4 \mu \mathrm{l}$ of dNTP (25 mM each) (Promega); $0.1 \mu \mathrm{l}$ of SuperScript IV (Invitrogen); $0.2 \mu \mathrm{l}$ of Actinomycin D $(1,000 \mathrm{ng} / \mu \mathrm{l})($ Nacalai Tesque); and $5.9 \mu \mathrm{l}$ of distilled water). Now the volume of the mix is $20 \mu \mathrm{l}$.

6. For the reverse transcription step, incubate the mixture at $25^{\circ} \mathrm{C}$ for $10 \mathrm{~min}$, followed by $10 \mathrm{~min}$ at $50^{\circ} \mathrm{C}$. Inactivate SuperScript IV by heating the mixture at $80^{\circ} \mathrm{C}$ for $15 \mathrm{~min}$. Then add $24 \mu \mathrm{l}$ of AMPure XP (Beckman Coulter) and $12 \mu \mathrm{l}$ of $99.5 \% \mathrm{EtOH}$, and perform the purification step according to the manufacturer's manual.

The detail of purification with AMPure XP beads in this protocol is as below:
a. Mix by pipetting.
b. Room temperature, 5 min.
c. Put on magnet, $5 \mathrm{~min}$, remove supernatant.
d. Add $70 \mu \mathrm{l}$ of $70 \% \mathrm{EtOH}$ on the magnet stand and remove it. Repeat this step again.
e. Dry up for $1 \mathrm{~min}$.
f. Add $10.0 \mu \mathrm{l}$ or other Nuclease free water, mix by pipetting.
g. R.T. for $1 \mathrm{~min}$.
h. Put on magnet, collect $10.0 \mu \mathrm{l}$ or other of supernatant to 384-well PCR plate.

7. Elute the transcription product with $10 \mu \mathrm{l}$ of distilled water. Mix the purified DNA/RNA hybrid solution without beads with the second strand synthesis master mix [2 $\mu \mathrm{l}$ of 10x Blue Buffer (Enzymatics), $1 \mu \mathrm{l}$ of dUTP/NTP mix (Fermentas), $0.5 \mu \mathrm{l}$ of frozen stock of $100 \mathrm{mM}$ DTT, $0.5 \mu \mathrm{l}$ of RNase $\mathrm{H}$ (Enzymatics), $1 \mu \mathrm{l}$ of DNA polymerase I (Enzymatics), and $5 \mu \mathrm{l}$ of distilled water] The final volume of the mixture is $20 \mu$. 
8. Incubate the mixture at $16{ }^{\circ} \mathrm{C}$ for $4 \mathrm{~h}$. Purify dsDNA with $24 \mu \mathrm{l}$ of AMPure XP according to the manufacturer's manual. Elute the purified dsDNA with $10 \mu \mathrm{l}$ of distilled water. Use $5 \mu \mathrm{l}$ of the dsDNA solution for the following step.

9. Perform end-repair, A-tailing and adapter ligation using a KAPA Hyper Prep kit (KAPA Biosystems) with $1 / 10 \times$ volume of the solutions according to the manufacturer's manual. Use $1 \mu \mathrm{l}$ of $0.1 \mu \mathrm{M}$ Y-shape adapter (Recipe 3, Nagano et al., 2015) in the adapter ligation step and incubate for $15 \mathrm{~min}$ at $20^{\circ} \mathrm{C}$. The final volume of this reaction product is $11 \mu \mathrm{l}$.

10. Perform size selection of the ligation product with $5.5 \mu \mathrm{l}$ of AMPure XP, resulting in $0.32 \times$ AMPure XP. The first size-selection is conducted at the smaller ratio than the second due to strong viscosity of ligation reaction mix. Elute the purified dsDNA using $10 \mu \mathrm{l}$ of distilled water. Carry out the second round of size selection with $10 \mu \mathrm{l}$ of AMPure XP, resulting in $0.5 \times$ AMPure XP. Elute the size-selected ligation product with $15 \mu \mathrm{l}$ of $10 \mathrm{mM}$ Tris- $\mathrm{HCl}, \mathrm{pH}$ 8.0. Add $1 \mu \mathrm{l}$ of uracil DNA glycosylase (UDG) (Enzymatics) to the size-selected ligation product. The volume of the mix is $16 \mu$ l.

11. Incubate the mixture at $37^{\circ} \mathrm{C}$ for $30 \mathrm{~min}$ to exclude the second-strand DNA.

12. For library amplification, mix $2 \mu \mathrm{l}$ of the UDG-digested DNA with $1 \mu \mathrm{l}$ of $2.5 \mu \mathrm{M}$ index primer (CAAGCAGAAGACGGCATACGAGATXXXXXXXXGTGACTGGAGTTCAGACGTGT,

XXXXXXXX indicates index sequence in the supplemental file) (Nagano et al., 2015), $1 \mu \mathrm{l}$ of 10 $\mu \mathrm{M}$ universal primer

(AATGATACGGCGACCACCGAGATCTACACTCTTTCCCTACACGACGCTCTTCCGATCT)

(Nagano et al., 2015), $0.5 \mu \mathrm{l}$ of distilled water and $5 \mu \mathrm{l}$ of KAPA HiFi HotStart ReadyMix (2x) (KAPA Biosystems). The volume of the mix is $10 \mu \mathrm{l}$.

13. Amplify DNA fragments with the adapters and an index sequence using a thermal cycler with the following program: denature at $94^{\circ} \mathrm{C}$ for $2 \mathrm{~min}, 18$ cycles at $98^{\circ} \mathrm{C}$ for $10 \mathrm{~s}, 65^{\circ} \mathrm{C}$ for $30 \mathrm{~s}$, $72{ }^{\circ} \mathrm{C}$ for $30 \mathrm{~s}$ as an amplification step, and $72{ }^{\circ} \mathrm{C}$ for $5 \mathrm{~min}$ for the final extension. Then perform two rounds of size selection to remove adapter dimer with an equal volume of AMPure XP to the library solution with $10 \mu \mathrm{l}$ of D.W. for elution. Next elute the purified library with $10 \mu \mathrm{l}$ of distilled water. Now, you can pool the libraries, if needed. Also use library quantification kit (e.g., KAPA Library Quantification Kit Illumina (KAPA Biosystems)) to determine the concentration followed by pooling.

14. Take out $1 \mu \mathrm{l}$ of the purified library for electrophoresis using an Agilent High Sensitivity DNA kit (Agilent Technologies) to evaluate quality. The typical concentration of the library is more than $1 \mathrm{ng} / \mathrm{\mu l}$, and the size distribution is shown below (Figure 2). 


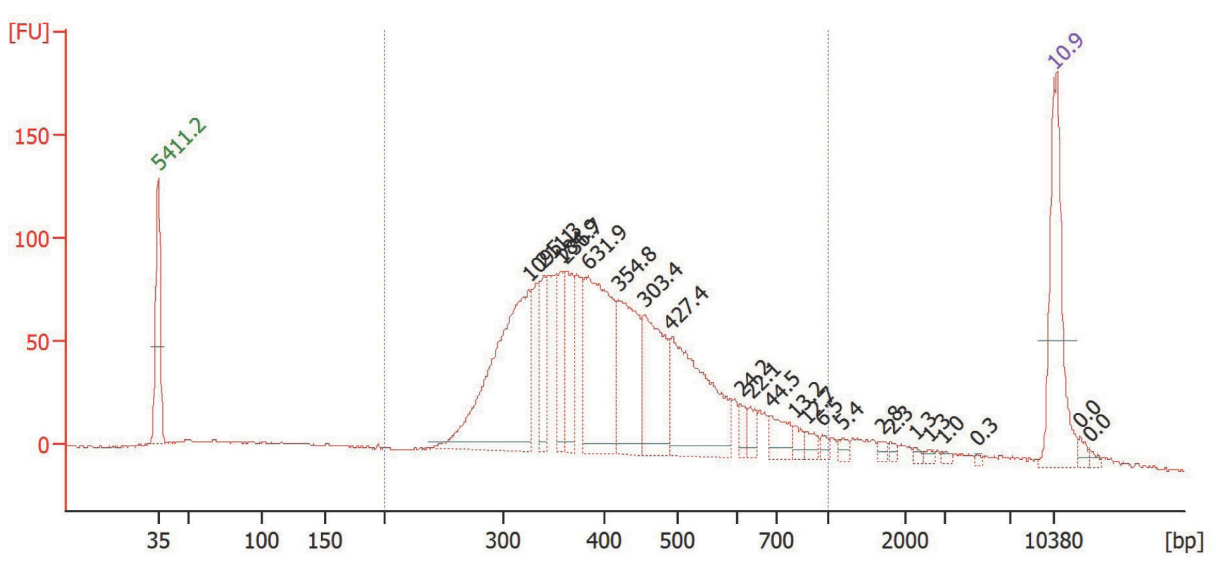

Figure 2. The typical size distribution of the final product of this protocol. A result from electrophoresis produced with Agilent High Sensitivity DNA kit.

\section{$\underline{\text { Recipes }}$}

1. $2 \times$ binding buffer

$40 \mathrm{mM}$ Tris- $\mathrm{HCl}, \mathrm{pH} 7.6$

$2 \mathrm{M} \mathrm{LiCl}$

4 mM EDTA

2. Washing buffer

$10 \mathrm{mM}$ Tris- $\mathrm{HCl}, \mathrm{pH} 7.6$

$0.15 \mathrm{M} \mathrm{LiCl}$

1 mM EDTA

3. Y-shape adapter
A
mixture
of
100
$\mathrm{mM}$
adapters
$\left(5^{\prime}-\right.$

A*IA*TGATACGGCGACCACCGAGATCTACACTCTTTCCCTACACGACGCTCTTCCGAT*C* T-3' 5'-/5Phos/-G*A*TCGGAAGAGCACACGTCTGAACTCCAGTC*A*C-3'.

${ }^{*}$ signifies a phosphonothioate bond. /5Phos/signifies a phosphorylation) is annealed using a thermal cycler with the following program:

$95^{\circ} \mathrm{C}$ for $2 \mathrm{~min}$, slow-cooled to $25^{\circ} \mathrm{C}\left(0.1^{\circ} \mathrm{C} / \mathrm{s}\right)$, followed by $30 \mathrm{~min}$ at $25^{\circ} \mathrm{C}$. The annealed adapter $(50 \mu \mathrm{M})$ is diluted into $0.1 \mu \mathrm{M}$ with $\mathrm{D}$.W and stored at $-20^{\circ} \mathrm{C}$.

\section{Acknowledgments}

This work was supported by the JST CREST JPMJCR15O2 to A.J.N. This protocol was modified from the method described in Nagano et al., 2015. 


\section{Competing interests}

We have no conflicts of interest or competing interests.

\section{$\underline{\text { References }}$}

1. Alpern, D., Gardeux, V., Russeil, J., Mangeat, B., Meireles-Filho, A. C. A., Breysse, R., Hacker, D. and Deplancke, B. (2019). BRB-seq: ultra-affordable high-throughput transcriptomics enabled by bulk RNA barcoding and sequencing. Genome Biol 20(1): 71.

2. Kamitani, M., Kashima, M., Tezuka, A. and Nagano, A. J. (2019). Lasy-Seq: a high-throughput library preparation method for RNA-Seq and its application in the analysis of plant responses to fluctuating temperatures. Sci Rep 9(1): 7091.

3. Kumar, R., Ichihashi, Y., Kimura, S., Chitwood, D. H., Headland, L. R., Peng, J., Maloof, J. N. and Sinha, N. R. (2012). A high-throughput method for Illumina RNA-Seq library preparation. Front Plant Sci 3: 202.

4. Muir, P., Li, S., Lou, S., Wang, D., Spakowicz, D. J., Salichos, L., Zhang, J., Weinstock, G. M., Isaacs, F., Rozowsky, J. and Gerstein, M. (2016). The real cost of sequencing: scaling computation to keep pace with data generation. Genome Biol 17: 53.

5. Nagano, A. J., Honjo, M. N., Mihara, M., Sato, M. and Kudoh, H. (2015). Detection of plant viruses in natural environments by using RNA-Seq. Methods Mol Biol 1236: 89-98.

6. Townsley, B. T., Covington, M. F., Ichihashi, Y., Zumstein, K. and Sinha, N. R. (2015). BrADseq: Breath Adapter Directional sequencing: a streamlined, ultra-simple and fast library preparation protocol for strand specific mRNA library construction. Front Plant Sci 6: 366. 